\title{
BEHAVIORAL CONTRACTING WITHIN THE FAMILIES OF DELINQUENTS*
}

\author{
RICHARD B. STUART $\dagger$ \\ The University of Michigan
}

\begin{abstract}
Summary-The technique of behavioral contracting is used to strengthen the control of family and school over the behavior of delinquents. A behavioral contract is a means of scheduling the exchange of positive reinforcements among two or more persons. The use of these contracts is predicated upon four assumptions: (1) receipt of positive reinforcements in interpersonal exchanges is a privilege rather than a right; (2) effective interpersonal agreements are governed by the norm of reciprocity; (3) the value of an interpersonal exchange is a direct function of the range, rate and magnitude of the positive reinforcements mediated by that exchange; and (4) rules create freedom in interpersonal exchanges. The use of a behavioral contract with one delinquent girl is described and analyzed using Markovian methods.
\end{abstract}

ANY INTERVENTION program intended for use with delinquents must first define a specific subpopulation as a target group. Delinquents may be subdivided according to whether their predominant offenses are or are not classifiable as adult crimes, whether they are initial or chronic offenders, and whether or not they reside in environments replete with constructive resources which can be mobilized to their advantage. For many delinquents [e.g., for 24 per cent of the adolescent male wards of one Michigan county juvenile court (Huetteman, Briggs, Tripodi, Stuart, Heck and McConnell, 1970)], violations of parental authority and other uniquely juvenile offenses (e.g., possession of alcoholic beverages and failure to attend school) constitute the only "crimes" ever recorded. Many engage in chronically dysfunctional interactions with their families and schools, both of which settings contain the rudiments of effective behavioral controls.

A continuum of short- to intermediate-term dispositional goals is available for working with this group (see Fig. 1). Ranging from maintaining the youth in his natural home environment, through a series of semi-institutional settings, to institutionalization in correctional or psychiatric settings, the points along the continuum vary according to the extent to which they provide social structure and make use of natural forces of behavioral control in the community. Recent studies have shown that the more potent the influence of the natural environment throughout treatment, the greater the likelihood that behavioral changes will be maintained following treatment. For example, it has been shown that two groups of delinquents, who spent an average of 131.6 days in psychiatric settings or 91.8 days in correctional settings of every year that they were wards of the juvenile court, actually committed more offenses than another very similar group who were not institutionalized (Huetteman et al., 1970). Even stronger support of the need for community treatment is found in a large-scale review of many rehabilitation programs, which concluded with the finding that:

*This paper was prepared for presentation at the 78th Annual Meeting of the American Psychological Association, Miami Beach, Florida, 6 September 1970. The research from which this paper was derived was funded by a grant of U.S. 314(d) funds administered by the State of Michigan Department of Mental Health. The author wishes to acknowledge the contribution made to this paper by his colleagues (Drs. Edward Heck, Tony Tripodi and James V. McConnell) and the editorial assistance of Miss Lynn Nilles.

tRequests for reprints should be addressed to the author at School of Social Work, 1065 Frieze Building, University of Michigan, Ann Arbor, Michigan 48104. 
- since severe penalties do not deter more effectively, and since prisons do not rehabilitate, and since the criminal justice system is inconsistent and has little quantitative impact on crime, the best rehabilitative possibilities would appear to be in the community (Harlow, 1970, pp. 33-34).

Community treatment for large numbers of delinquents will be possible only when techniques have been developed which (a) are effective, (b) require comparatively little time for administration, (c) can extend family influence to control behavior in a number of different situations, and (d) can be administered by paraprofessionals. It is suggested that behavioral contracting, to be described and illustrated in this paper, is one technique which meets each of thesc requirements and can be employed as a tactic in every instance in which efforts are made to strengthen the place of an adolescent in a natural, foster, or group home environment.

\section{RATIONALE}

At the core of the effort to use behavioral contracting to combat delinquency are two assumptions. First, it is assumed that the family plays a critical role in the etiology of delinquency when certain dysfunctional family interaction patterns coexist with a paucity of opportunities for acceptable performance in the community (Rodman and Grams, 1967) and when peer pressures are conducive to deviant behavior (Burgess and Akers, 1969). The family may function as a pathogen in two ways. First, the family may model and differentially reinforce patterns of antisocial behavior (Bandura and Walters, 1963). Second, the family may inadequately reinforce prosocial behavior in comparison with the reinforcement of antisocial behavior available in the community. Stuart (1970a) showed that the family of delinquents could be differentiated from the families of nondelinquents on the basis of their low rate of positive exchanges, while Patterson and Reid (1971) demonstrated that interactional patterns of coercion are more common within delinquent families than patterns of reciprocity.

The second assumption is that the family in many instances is a potentially powerful if not the only force available to aid the delinquent in acquiring prosocial responses. Over 15 years ago, Katz and Lazarsfeld (1955) clearly showed that in studies of attitude formation and change the family accounts for over two-thirds of the observed variance. Modern sociologists such as Schafer and Polk (1967) have shown that most social agencies, including schools in particular, are more oriented toward removing than rehabilitating the delinquent. Therefore it is essential to both eliminate the pathogenic elements of the family and to harness its vast power in order to mount constructive programs to aid delinquents.

\section{BEHAVIORAL CONTRACTS}

A behavioral contract is a means of scheduling the exchange of positive reinforcements between two or more persons. Contracts have been used

Fig. 1. Continuum of dispositional goals for the tReatment of JuVenile delinquents.

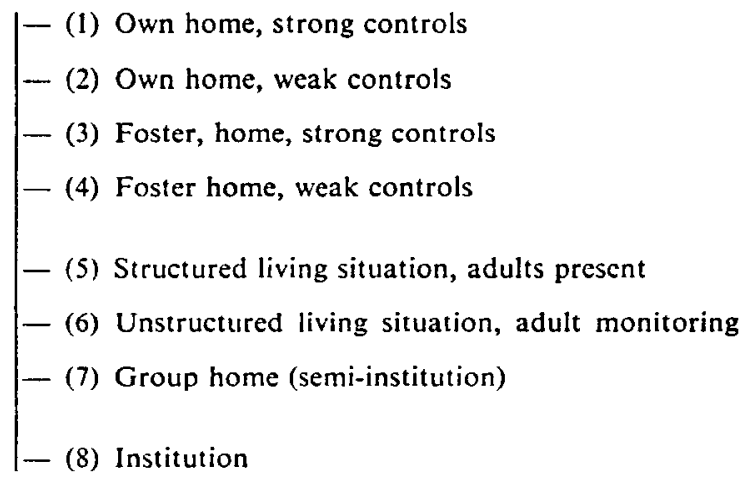


when reciprocal patterns of exchange have broken down within families (Carson, 1969; Tharp and Wetzel, 1969) or in efforts to establish reciprocal exchanges from the outset in formal relationships in therapeutic (Sulzer, 1962) and scholastic (Homme, Csanyi, Gonzales and Rechs, 1969) settings. Contracts structure reciprocal exchanges by specifying: who is to do what, for whom, under what circumstances. They therefore make explicit the expectations of every party to an interaction and permit each to determine the relative benefits and costs to him of remaining within that relationship (Thibaut and Kelley, 1959). Furthermore, by making roles explicit for family members, contracts enhance the likelihood that responsibilities will be met, and by postulating reciprocal exchanges within families, contracts contribute to interactional stability. Finally, because privileges and responsibilities are fairly wellstandardized across families the execution of behavioral contracts in time-limited, highpressure settings is quite feasible.*

Behavioral contracting with families rests upon four assumptions. First, it is assumed that:

Receipt of positive reinforcements in interpersonal exchanges is a privilege rather than a right.

A privilege in this sense is a special prerogative which one may enjoy at the will of another person upon having performed some qualifying task. For example, states bestow driving privileges upon citizens who qualify for this privilege by passing certain performance tests and by driving with standard prudence. In contrast, a right implies undeniable and inalienable access to a prerogative. Furthermore, a right cannot be denied, no matter what an individual might do. In modern society there are virtually no rights beyond the right of the individual to think as he may choose. For example, people in a democratic society have the privilege to say what they think, but not to shout "fire" in a crowded theater no matter how hard it is to find a seat.

Within families it is the responsibility of one person to grant the privileges requested by another on a reciprocal basis. For example, an adolescent might wish free time-this is his privilege-and it is his parents' responsibility to provide this free time. However, the parents may wish that the adolescent attend school each day prior to going out in the evening-the adolescent's school attendance is their privilege and it is his responsibility to do as they ask. Privileges may, of course, be abused. Thus a parent might wish to know where his adolescent goes when he leaves home, but if the parents attack the adolescent when they learn of his plans, they have failed to meet their responsibility, i.e., use the information constructively. Thus it is appropriate to consider as a part of the definition of a privilege the conditions for its appropriate use.

A second assumption underlying the use of behavioral contracts is:

\section{Effective interpersonal agreements are governed by the norm of reciprocity.}

A norm is a "behavioral rule that is accepted, at least to some degree, by both members of the dyad (Thibaut and Kelley, 1959, p. 129)." Norms serve to increase the predictability of events in an interaction, permit the resolution of conflicts without recourse to power and have secondary reinforcing value in and of themselves (Gergen, 1969, pp. 73-74). Reciprocity is the norm which underlies behavioral contracts. Reciprocity implies that "each party has rights and duties (Gouldner, 1960, p. 169)," and further, that items of value in an interchange must be exchanged on an equity or quid pro quo ("something for something [Jackson, 1965, p. 591]") basis. Therefore, inherent in the use of behavioral contracts is acceptance of the notion that one must compensate his partner fairly for

* Behavior Change Systems (3156 Dolph Drive, Ann Arbor, Michigan 48103) makes available behavioral contracting kits, including code book and computer compatable code forms in addition to standardized materials for use with clients. 
everything which is received, that is, there are no gifts to be expected within contractual relations.

A third principle basic to the use of behavioral contracts states that:

The value of an interpersonal exchange is a direct function of the range, rate, and magnitude of the positive reinforcements mediated by that exchange.

Byrne and Rhamey (1965) have expressed this assumption as a law of interpersonal behavior postulating that one's attraction to another will depend upon the proportion and value of positive reinforcements garnered within that relationship. In a similar vein, Mehrabian and Ksionsky (1970) have reviewed many years of social psychological research supporting the conclusion that: "Situations where affiliative behavior increases positive reinforcement ... induce greater affiliative behavior (p. 115)."

In the negotiation of behavioral contracts, through a process of accommodation (Gergen, 1969 , p. 73), each party seeks to offer to the other the maximum possible rate of positive reinforcement because the more positive rein- forcements which are emitted, the more will be received. In this sense, each positive offered represents an individual's "investment" in a contract, and each privilege received represents "return on an investment." Therefore a good intrafamilial contract encourages the highest possible rate of mutual reinforcement as represented by the following diagram (Fig. 2) in which $\mathrm{CO}_{\mathrm{FMA}}$ implies the optimal choice for father, mother and adolescent, $\mathrm{CO}_{\mathrm{F} / \mathrm{MA}}$ the optimal choice for father which the mother and adolescent will accept, etc., and $k$ a valuedetermining constant.

The fourth and final assumption basic to the concept of behavioral contracting is:

\section{Rules create freedom in interpersonal exchanges.}

When contracts specify the nature and condition for the exchange of things of value, they thereby stipulate the rules of the interaction. For example, when an adolescent agrees that she will visit friends after school (privilege) but that she will return home by 6.00 p.m. (responsibility), she has agreed to a rule governing the exchange of reinforcers. While the rule delimits

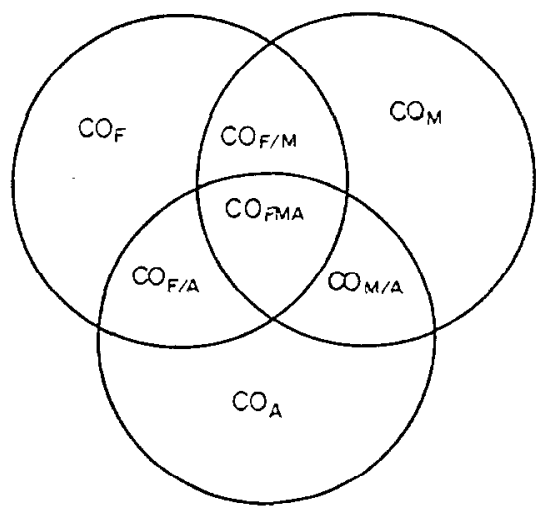

FIG. 2. 
the scope of her privilege, it also creates the freedom with which she may take advantage of her privilege. Without this rule, any action taken by the girl might have an equal probability of meeting with reinforcement, extinction or punishment. If the girl did not have a clear-cut responsibility to return home at 6.00 p.m. she might return one day at 7.00 and be greeted warmly, return at 6.00 the next day and be ignored, and return at 5.30 the following day and be reprimanded. Only by prior agreement as to what hour would be acceptable can the girl insure her freedom, as freedom depends upon the opportunity to make behavioral choices with knowledge of the probable outcome of each alternative.

Just as contracts produce freedom through detailing reciprocal rule-governed exchanges, so must contracts be born of freedom, since coerced agreements are likely to be violated as soon as the coercive force is removed. Therefore effective behavioral contracts must be negotiated with respect to the following paradigm:

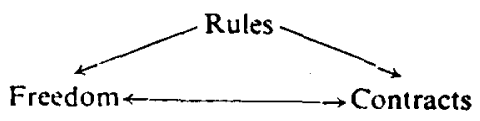

\section{ELEMENTS OF BEHAVIORAL CONTRACTS}

Good behavioral contracts contain five elements. First, the contracts must detail the privileges which each expects to gain after fulfilling his responsibilities. Typical privileges used in behavioral contracts in the families of delinquents include free time with friends, spending money, choice of hair and dress styles and use of the family car for the adolescent. Second, good contracts must detail the responsibilities essential to securing each privilege. Again, in the families of delinquents, responsibilities typically include maintenance of minimally adequate school attendance and performance, maintenance of agreed-upon curfew hours, completion of household chores and keeping parents informed about the adolescent's whereabouts. Every effort is made to restrict privileges to prosocial behaviors and to keep responsibilities to a minimum. The former is necessary if the family is to effectively serve as an agent of social control. The latter is necessary because the parents of teenage children control comparatively few salient reinforcements and must use those which are controlled with sufficient care to maintain desired behavior. If the number of responsibilities is increased without comparable increase in the value of privileges offered, little or no reinforcement will be provided for the new responsibilities and they are unlikely to be met, weakening the general credibility of the contract.

As an added requirement, the responsibilities specified in a family contract must be monitorable by the parents, for if the parents cannot determine when a responsibility has been fulfilled, they cannot know when to properly grant a privilege. Therefore there are some things which are beyond the scope of behavioral contracts, such as where an adolescent goes when he is not at home or whom he sees as friends. The single exception to this rule is the possibility of using school attendance and performance as responsibilities. While it can be argued that classroom behavioral management is the primary responsibility of teachers (Stuart, 1970b), it is often not possible for a behavior modifier to gain access to any or all of an adolescent's teachers (Bailey, Phillips and Wolf, 1970), so he may be required to attempt to control behavior in school with reinforcements mediated in the home. When this is done, it is essential to arrange for systematic feedback to be provided by the teacher to the parent describing the teenager's attendance and performance in class. A simple card brought for a teacher's signature every day or every week by the teenager is a sufficient and very practical means of securing this feedback (see Fig. 3).

The third element of a good behavioral contract is a system of sanctions for failure to meet responsibilities. While in one sense the possibility of time out from privileges should be adequate to insure the completion of responsibilities, there are obviously periods in the 


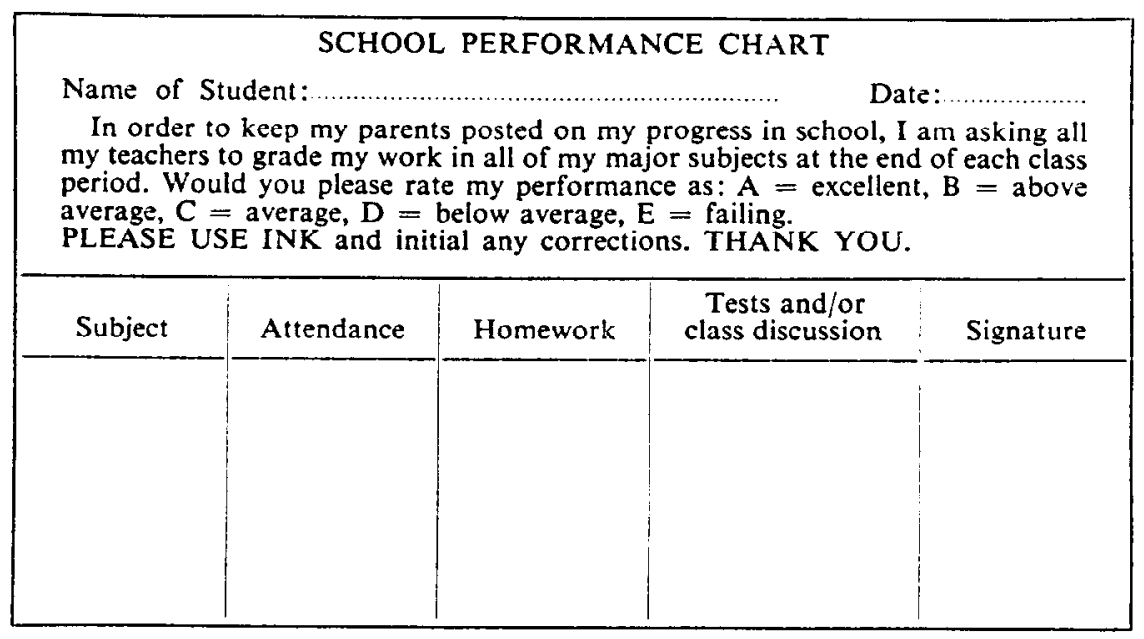

FIG. 3.

course of family life when this is not the case. At all times, behavior is under multiple contingency control (Stuart, 1970c), and in certain instances it is more reinforcing to violate the contract and to forfeit a subsequent privilege than to garner the rewards of adhering to the terms of the contract. At these times the existence of sanctions may tip the balance of a behavioral choice toward compliance with contractual obligations. Furthermore, sanctions have an added advantage: they provide the aggrieved party with a temperate means of expressing his displeasure. In families without explicit or understood behavioral contracts, the failure of a child to meet curfew is often met with threats of long-term "grounding". Faced with the threat of not being permitted to go out for weeks on end, the teenager is often pursuaded to violate his contract even further and remain out later because the magnitude of the penalty is fixed and not commensurate with the magnitude of his violation.

When sanctions are built into the contract, they may be of two types. One is a simple, linear penalty such as the requirement that the adolescent return home as many minutes early the following day as he has come in late on the preceding day. The second type of sanction is a geometric penalty which doubles or triples the amount of make-up time due following contract violations. It is probably best to combine both types of sanctions, making certain that lateness does not reach a point of diminishing return when it would actually be impractical for the adolescent to return home at all because he would incur no greater penalty for continued absence.

The fourth element in a good behavioral contract is a bonus clause which assures positive reinforcement for compliance with the terms of the contract. Much behavior control within families consists of "negative scanning" (Stuart, 1969) or the extinction of positive responding (by ignoring it) coupled with the severe punishment of negative responding. The effect of this punishment is, of course, to strengthen negative behavior as a consequence of the facts that attention follows negative behavior and does not follow positive responses (Madsen, Becker, Thomas, Kosar and Plager, 1968). To counteract this, bonuses calling for permission to remain out longer than usual, extra money or extraordinary privileges such as the opportunity to have a party or to take a trip with friends are 
built into contracts as contingencies for extended periods of near-flawless compliance with contractual responsibilities.

When behavioral contracts are well executed, each member of the family is assured of receiving the minimum level of positive reinforcement (privileges) necessary to sustain his participation in the interaction. Furthermore, each party to the agreement is provided with a means of responding to contract violations and each is reinforced for long chains of desirable responses. The contract is not complete, however, unless a means is also built in for keeping track of the rates of positive reinforcements given and received. This is accomplished through feedback systems which serve two functions. First, they cue each individual as to how to respond in order to earn an additional inducement. Second, they signal each person when to reinforce the other. Furthermore, the provision of feedback in this context also sets the occasion for positive comments which themselves strengthen prosocial behavior. The exchange of feedback is facilitated by the use of a behavioral monitoring form calling for each person to check off the fulfillment of his own responsibilities (which includes provision of the privileges of the others).

\section{ILLUSTRATION}

A behavioral contract constituted the primary treatment procedure in the management of a 16-year-old girl who was referred to the Family and School Consultation Project by the local juvenile court. At the time of referral, Candy Bremer* had been hospitalized as an inpatient at a local psychiatric hospital following alleged promiscuity, exhibitionism, drug abuse and home truancy. Associated with these complaints was an allegation by her parents that Candy engaged in chronically antagonistic exchanges within the family and had for a year done nearfailing work in school. Owing to the cost of private psychiatric care, the parents sought hospitalization at state expense by requesting *Pseudonym. that the juvenile court assume wardship. After initiating this action, the parents were informed by a court-appointed attorney representing their daughter that the allegations would probably not stand up in court. The parents accordingly modified their request to a petition that the court place Candy on the consent docket affording quasi-ward status without termination of parental rights.

At the time of referral, Mr. and Mrs. Bremer were 64 and 61 years old respectively, and both were physically ill-Mr. Bremer suffering from emphysema and Mrs. Bremer from a degenerative bone disease in her hip. Both holding college degrees, Mr. Bremer performed scholarly work at home on a part-time basis while Mrs. Bremer worked as a medical secretary. Candy, the third of their three children, was 20 years younger than her oldest sister. The Bremers resided in a very small ranch-type home which lacked a basement, so privacy could only be found in the bedrooms.

Initially, Mr. and Mrs. Bremer wished to maintain virtually total control over Candy's behavior. They were reluctantly willing to accept her at home but established as conditions that she adhere to a punishing curfew which allowed her out of the home for periods averaging 2 to 3 hours per summer day. Great effort was expended to convince the parents of the need to modify their expectations and to modify a continuous chain of negative interactions. However, when both of these efforts failed, it was decided to execute a behavioral contract anyway, because the problems expected at home seemed less negative than the probable consequences of continued institionalization and because it was hoped that a more realistic contract could be effectuated as time progressed. Within 3 weeks of the start of the contract, Candy was reported to be sneaking out of her bedroom window at night, visiting a local commune and returning home before dawn. It was found that over a 24-day period there were eight major contract violations, and the probability of an extended series of days of contract compliance was quite 
small* (see Fig. 4). While it was deemed vital to introduce more privileges for Candy, it seemed imprudent to do this as a contingency for her having violated her contract in the past. Finally it was decided to do two things. A new contract, which was far more permissive, was introduced (see Fig. 5), accompanied by a new monitoring sheet (see Fig. 6), but a new court order was requested and granted which proscribed Candy from entering the communes. Candy was made to understand that, should she be found in either commune, not she but the commune members would be liable to prosecution for contributing to the delinquency of a minor as they had been officially informed of the limitation placed upon Candy's activities.

As seen in Fig. 4, this modified contract was quite effective, increasing the rate of compliance to the contract terms to a very respectable high rate. When court wardship was terminated and the contract was the sole behavioral prosthesis, Candy's behavior actually continued to improve.

Fig. 4. Candy Bremer-Curfew maintenance

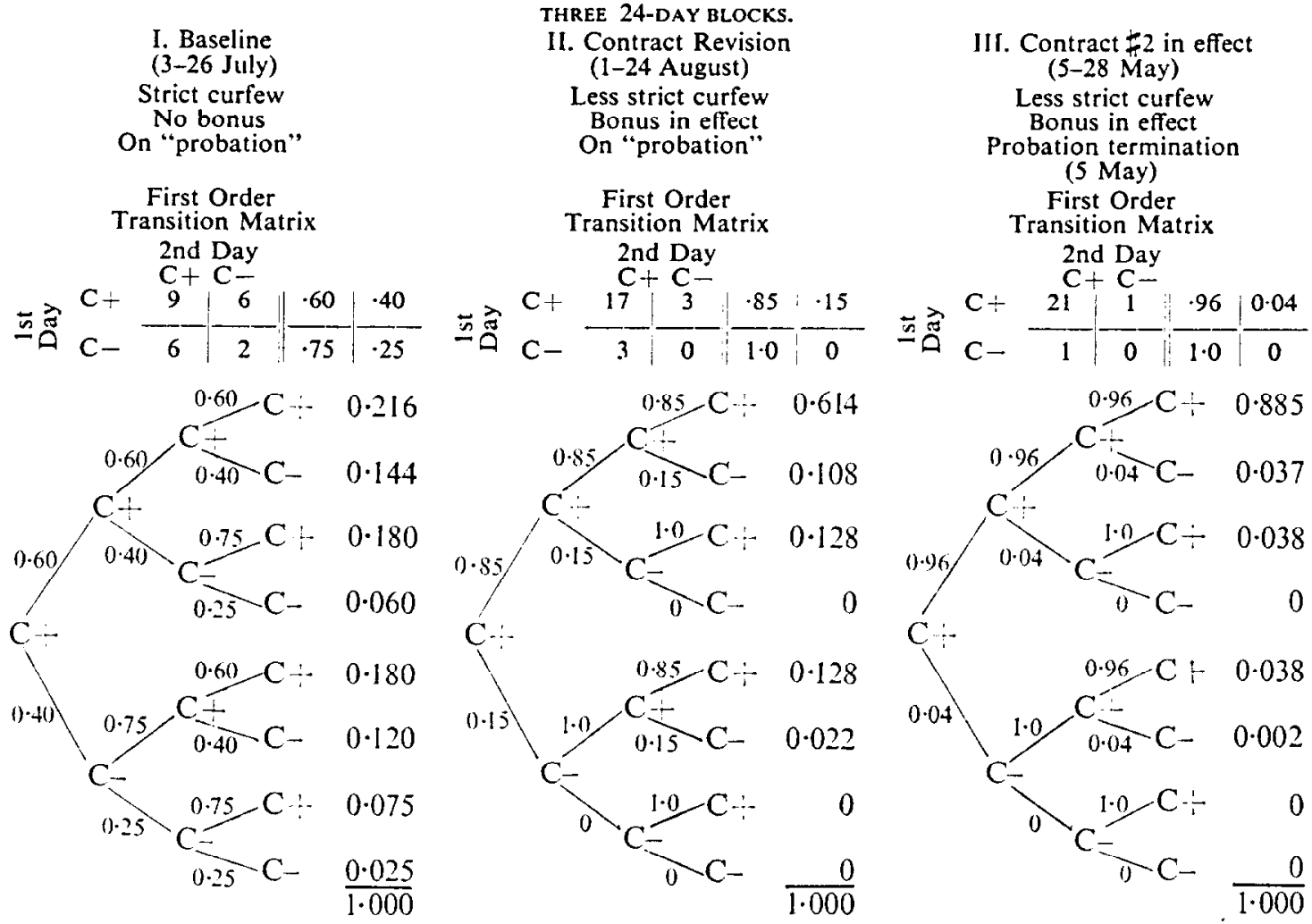

* These and subesquent data were evaluated using a Markovian chain designed to make predictions of future behavior based upon observation of past behavior in 24-day blocks. For an extended discussion of this procedure, see Kemeny, Mirkil, Snell and Thompson (1959). In simplified form, the analysis is completed through the following steps: (1) write the series of dichotomous observations as a series of,+- notations $(+--++-+$, etc.); (2) count the number of,,-++--+ and - - sequences, recording the totals in a $2 \times 2$ table; (3) compute the proportion of $++v s+-$ and $-+v s--$ sequences and enter these decimals in the appropriate cells of a $2 \times 2$ table; (4) draw as many Markovian tree forms as needed following the illustration in Fig. 3; (5) for each ,,+++--+ and - - series, write in the proportions obtained in step $3 ;(6)$ multiply all such entries in each series. CHECks: (a) entries at each pair of branching alternatives $\left(\mathrm{C}+\frac{0.6 \mathrm{C}+}{0.4 \mathrm{C}-}\right)$ must total 1.00 $(0 \cdot 6+0 \cdot 4)$. (b) The probability of all series must total 1.00 .

Interprefation. The obtaincd values may be interpreted as the probability that each series, (e.g. $++-\rightarrow$ will occur, relative to all other series, assuming constant conditions. 
Fig. 5. Behavioral Contract.

General

Privileges

RESPONSIBILITIES

In exchange for the privilege of remaining together and preserving some semblance of family integrity, Mr. and Mrs. Bremer and Candy all agree to

concentrate on positively reinforcing each other's behavior while diminishing the present overemphasis upon the faults of the others.

Specific

In exchange for the privilege of riding the bus directly from school into town after school on school days

In exchange for the privilege of going out at 7.00 p.m. on one weekend evening without having to account for her whereabouts

In exchange for the privilege of going out a second weekend night

In exchange for the privilege of going out between $11.00 \mathrm{a} . \mathrm{m}$. and $5.15 \mathrm{p} . \mathrm{m}$. Saturdays, Sundays and holidays

In exchange for the privilege of having Candy complete household chores and maintain her curfew

\section{Bonuses and Sanctions}

If Candy is $1-10$ minutes late

If Candy is $11-30$ minutes late

If Candy is $31-60$ minutes late

For each half hour of tardiness over one hour. Candy

Candy may go out on Sunday evenings from 7.00 to $9.30 \mathrm{p} . \mathrm{m}$. and either Monday or Thursday evening

Candy may add a total of two hours divided among one to three curfews

Candy agrees to phone her father by 4.00 p.m. to
tell him that she is all right and to return home by 5.15 p.m.

Candy must maintain a weekly average of " $B$ " in the academic ratings of all of her classes and must return home by 11.30 p.m.

Candy must tell her parents by 6.00 p.m. of her destination and her companion, and must return home by 11.30 p.m.

Candy agrees to have completed all household chores before leaving and to telephone her parents once during the time she is out to tell them that she is all right.

Mr. and Mrs. Bremer agree to pay Candy $\$ 1.50$ on the morning following days on which the money is earned.

she must come in the same amount of time earlier the following day, but she does not forfeit her money for the day.

she must come in 22-60 minutes carlier the following day and does forfeit her money for the day.

she loses the privilege of going out the following day and does forfeit her money for the day.

loses her privilege of going out and her money for one additional day.

if she abides by all the terms of this contract from Sunday through Saturday with a total tardiness not exceeding 30 minutes which must have been made up as above.

if she abides by all the terms of this contract for two weeks with a total tardiness not exceeding 30 minutes which must have been made up as above and if she requests permission to use this additional time by 9.00 p.m.

MONITORING

Mr. and Mrs. Bremer agree to keep written records of the hours of Candy's leaving and coming home and of the completion of her chores.

Candy agrees to furnish her parents with a school monitoring card each Friday at dinner. 


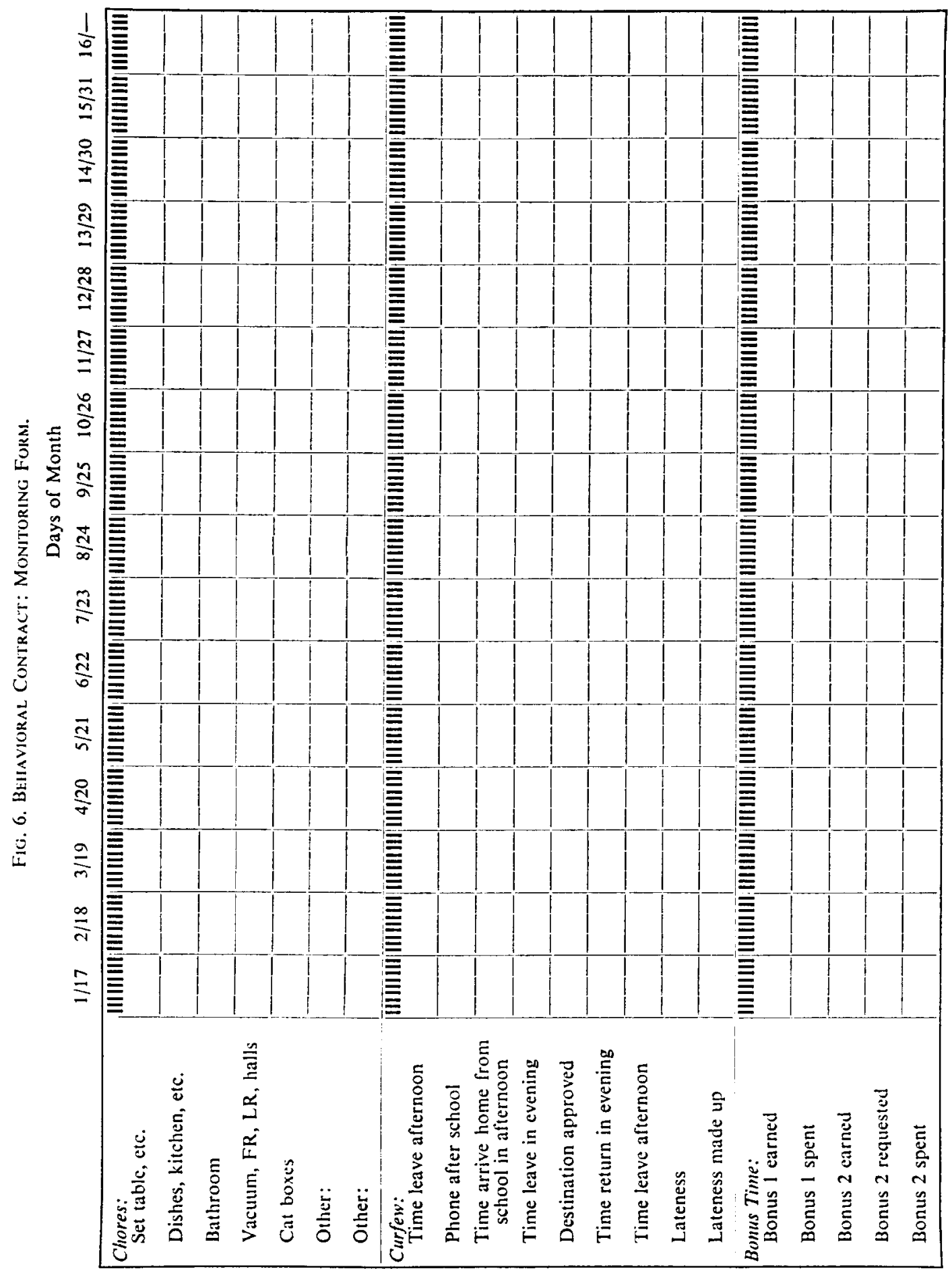




\section{DISCUSSION}

Behavioral contracting served as a very useful means of structuring a constructive interaction between Candy and her parents. By removing from the realm of contention the issues of privileges and responsibilities, the eliciters of many intrafamilial arguments were eliminated. When fights did occur, they tended to be tempered by the options available through the contract. The contract itself cannot account for a change in Candy's behavior; but the contract apparently served to assure the use of privileges such as free time and money as contingencies in the truest sense of the term.

The process of negotiating a contract through accommodation of each other's wishes (Gergen, 1969) might have been characterized as an "experience in form" by John Dewey. It appears to have laid the groundwork for a more effective interaction and in this case was adequate in and of itself. In other instances, it is likely that behavioral contracting could profitably be supplemented with interaction training for the parents, tutoring or vocational guidance for the adolescent or financial assistance for the family. The decision about which additional techniques should be employed is discretionary, but it is suggested that behavioral contracting be made a part of every plan to improve the interaction between an adolescent and his parents.

\section{REFERENCES}

Bailey J., Phillips E. and Wolf M. (1970) Homebased reinforcement and the modification of predelinquents' classroom behavior. Proceedings of the 78 th Annual Convention of the American Psychological Association, Vol. 5, 751-752 (Summary).

BANDURA A. and WALTERS R. H. (1963) Social Learning and Personality Development. Holt, Rinehart \& Winston, New York.

Burgess R. L. and AKers R. L. (1969) A differential association-reinforcement theory of criminal behavior. In Delinquency, Crime and Social Process (Edited by CRESSEY D. R, and WARD D. A.). Harper \& Row, New York.

BYRNE D. and RHAMEY R. (1965) Magnitude of positive and negative reinforcements as a determinant of attractions. J. Pers. Soc. Psychol. 2, 884-889.

CARSON R. C. (1969) Interaction Concepts of Personality. Aldine, Chicago.

GERGEN K. J. (1969) The Psycholozy of Behavior Exchange. Addison-Wesley, Reading, Massachusetts.

GOULDNER A. W. (1960) The norm of reciprocity: A preliminary statement. Amer. Soc. Rev. 25, 161-178.

HARLOW E. (1970) Intensive intervention: An alter- native to institutionalization. Crime and Delinquency Literature 2, 3-46.

Homme L. Csanyi A. P., Gonzales M. A. and Rechs J. R. (1969) How To Use Contingency Contracting in the Classroom. Research Press, Champaign, Illinois.

Huetteman M. J., Briggs J., Tripodi T., Stuart R. B., HECK E. T. and MCCoNnetL J. V. (1970) A descriptive comparison of three populations of adolescents known to the Washtenaw County Juvenile Court: Those referred for or placed in psychiatric hospitals, those placed in correctional settings, and those released following hearings. Unpublished manuscript, Family and School Consultation Project, Ann Arbor, Michigan.

JACKSON D. D. (1965) Family rules. Arch. Gen. Psychiat. 12, 589-594.

Katz E. and Lazarsfeld P. F. (1955) Personal Influence. Free Press, Glencoe, Illinois.

Kemeny J. G., Mirkil H., SNell J. L. and Thompson G. L. (1959) Finite Mathematical Structures. Prentice-Hall, Englewood Cliffs, New Jersey.

Madsen C. H. Jr., Becker W. C., Thomas D. R., Kosar L. and Plager E. (1968) An analysis of the reinforcing function of "sit down" commands. In Readings in Educational Psychology (Edited by R. K. PARKER). Allyn and Bacon, Boston.

MeHrabian A. and Ksionsky S. (1970) Models of affiliative behavior. Psychol. Bull. 74, 110-126.

Patterson G. R. and Reid J. (1971) Reciprocity and coercion: Two facets of social systems. In Behavior Modification in Clinical Psychology (Edited by $\mathrm{C}$. Neuringer and J. MichaeL). Appleton-CeniuryCrofts, New York.

RODMAN H. and Grams P. (1967) Juvenile delinquency and the family: A review and discussion. In President's Commission on Law Enforcement and Administration of Justice, Task Force on Juvenile Delinquency, Task Force Report: Juvenile Delinquency and Youth Crime. Washington, D.C.: U.S. Government Printing Office.

SCHAFER W. E. and PolK K. (1967) Delinquency and the schools. In President's Commission on Law Enforcement and Administration of Justice, Task Force on Juvenile Delinquency, Task Force Report: Juvenile Delinquency and Youth Crime. Washington, D.C.: U.S. Government Printing Office.

STUART R. B. (1969) Operant-interpersonal treatment for marital discord. J. Consult. Clin. Psychol. 33, 675-682.

StUART R. B. (1970a) Assessment and change of the communicational patterns of juvenile delinquents and their parents. In Advances in Behavior Therapy, 1969 (Edited by R. D. RuBiN). Academic Press, New York.

STUART R. B. (1970b) Behavior modification techniques for the education technologist. In Proceedings of the National Workshop on School Social Work, 1969-70 (Edited by R. C. SARRI). National Association of Social Workers, New York.

STUART R. B. (1970c) Situational versus self control in the treatment of problematic behaviors. In Advances in Behavior Therapy, 1970 (Edited by R. D. RUBiN). Academic Press, New York.

SULZER E. S. (1962) Research frontier: Reinforcement and the therapeutic contract. J. Counsel. Psychol. 9, 271-276.

THARP R. G. and WETZEL R. J. (1969) Behavior Modification in the Natural Environment. Academic Press, New York.

Thibaut J. W. and Kelley H. H. (1959) The Social Psychology of Groups. J. Wiley, New York. 